\title{
Practice of timely surgery for undescended testis during infancy to minimize risks of testicular malignancy and subfertility in adulthood
}

\author{
Ravibindu Ranawaka orcid.org/0000-0001-9150-7904 \\ Sri Lanka Journal of Child Health, 2018; 47(3): 288 \\ DOI: http://dx.doi.org/10.4038/sljch.v47i3.8558 \\ (Key words: undescended testis, testicular malignancy, subfertility)
}

The testes in a boy are located inside the abdominal cavity during early fetal life. They come down along the inguinal region (groin) to lie within the scrotum at birth. This journey sometimes stops along the pathway of descent, resulting in an undescended testis (UDT). Usually, no further descent of UDT occurs after birth in a baby born at term. In a pre-term baby, the descent may complete within a few weeks after birth. If left uncorrected, UDT has around 3.7 to 7.4 times the risk of developing into a cancer in adulthood. The fertility rate in adults with UDT is also low. The British Association of Paediatric Urologists recommends corrective surgery for UDT around six months of age to minimize the above risks.

The surgery to mobilize and bring the UDT back into the scrotum called "orchidopexy" is performed under general anaesthesia. The surgical approach depends on the location of the UDT. Low lying or palpable testis would have open orchidopexy while high lying or impalpable testis would have laparoscopic orchidopexy (also called keyhole surgery). The baby is usually sent home within one day of surgery. Usually, UDT is diagnosed at birth and parents are given a referral for a surgical consultation. Sometimes due to fear of surgery or lack of insight, parents delay getting a surgical opinion and these result in delayed orchidopexy.

One objective of a study performed at a tertiary care children's hospital in Sri Lanka on 200 consecutive boys with UDT was to find the age at surgical referral for orchidopexy. The study identified that only $27 \%$ (54/200) of babies with UDT had been referred for orchidopexy before they were six months of age. Rest of the results on the ages at surgical referral include: $22 \%(44 / 200)$ between $6.1-12$ months, $15.5 \%(31 / 200)$ between 12.1-24 months, $18 \%$ (36/200) between 2.1-5 years, $15 \%(30 / 200)$ between 5.1-10 years and $2.5 \%(5 / 200)$ between $10.1-12$ years. Twenty boys with UDT aged between $5-12$ years $(10 \%$ of the total number studied) had defaulted surgical clinic attendance despite prompt surgical referral made by a doctor at an earlier age.

It is very important for the parents to understand the gravity of the risks associated with UDT during adulthood and comply with medical advice for the benefit of their baby. Parents should seek prompt medical opinion if they have any concerns on the position of the baby's testes. Minimizing the risks of UDT related malignancy and subfertility is an achievable goal when we create understanding and awareness within our population.

\section{References}

1. Ranawaka UARS, Azmy FH, Banneheke RT, Nasar et al. Age at surgical referral and anatomical position of undescended testis in children presenting to the day surgical unit at Lady Ridgeway Hospital for Children, Colombo. Journal of the Postgraduate Institute of Medicine 2017; 4(1): E42 1- 4 http://doi.org/10.4038/jpgim.8144

2. Ranawaka R. Undescended testis. Sri Lanka Journal of Child Health, 2015; 44(3):163-4 